\title{
Т.Н. Смекалова ${ }^{1}$, М.Т. Кашуба
}

\section{ДИСТАНЦИОННОЕ ЗОНДИРОВАНИЕ В ИЗУЧЕНИИ ПОСЕЛЕНИЙ ПОЗДНЕГО БРОНЗОВОГО ВЕКА В СЕВЕРО-ЗАПАДНОМ КРЫМУ}

\begin{abstract}
АННОТАЦИЯ
Статья посвящена результатам применения комплексной междисциплинарной методики, сочетающей методы дистанционного зондирования, ГИС, геофизические и археологические исследования для выявления и изучения поселений эпохи поздней бронзы в Северо-Западном Крыму. Обнаружение этих поселений вызывает определённую сложность, так как они погребены под слоем почвы и не имеют прямых визуальных признаков. Выработана комплексная постадийная методика неразрушающего дистанционного исследования, включающая анализ космических снимков высокого разрешения в ресурсе Google Earth Pro, выявление перспективных участков по растительным и ландшафтным признакам, создание GPS маршрутов для наземной разведки, геофизические съёмки (магнитная и электромагнитная) на перспективных для выявления поселений позднего бронзового века, GPS картирование подъёмного материала, точечное археологическое зондирование. Все полученные результаты помещаются в единую геоинформационную систему, слои-подложки которой представляют собой детальные топографические, специальные почвенные, геологические, гидрогеологические, цифровые карты рельефа. В результате удалось выявить 45 новых поселений эпохи поздней бронзы, включая 19 поселений с двойными каменными загонами. Эти загоны были впервые открыты только благодаря применению дистанционных методов, в особенности магнитной съёмки. Окончательный ответ о существовании и планировке поселения эпохи позднего бронзового века до раскопок дают только магнитная и электромагнитные съёмки. Созданная ГИС по памятникам эпохи поздней бронзы в Северо-Западном Крыму будет служить как научным целям, так и для сохранения культурного наследия Республики Крым, что особенно актуально в условиях быстрого хозяйственного освоениях земель и строительства магистральных дорог.
\end{abstract}

КЛЮЧЕВЫЕ СЛОВА: данные дистанционного зондирования, ГИС, магнитная и электромагнитная съёмки, поселения позднего бронзового века, Северо-Западный Крым

\footnotetext{
${ }^{1}$ Крымский федеральный университет имени В.И. Вернадского, пр. Вернадского, д. 4, 295007, Симферополь, Россия; Национальный исследовательский центр “Курчатовский институт”, пл. Академика Курчатова, д. 1, 123182, Москва, Россия; e-mail: tnsmek@mail.ru

${ }^{2}$ Институт истории материальной культуры РАН, Дворцовая наб., д. 18, 191186, Санкт-Петербург, Россия; e-mail: mirra-k@yandex.ru
} 
Tatiana N. Smekalova ${ }^{1}$, Maja T. Kashuba ${ }^{2}$

\title{
REMOTE SENSING IN THE STUDY OF LATE BRONZE AGE SETTLEMENTS IN NORTH-WESTERN CRIMEA
}

\begin{abstract}
The article is devoted to the results of applying a comprehensive interdisciplinary methodology combining remote sensing methods, GIS, geophysical and archaeological research the Late Bronze for revealing and investigation of the Late Bronze Age settlements in the North-Western Crimea. The discovery of these settlements causes a certain difficulty, since they are buried under a layer of soil and do not have direct visual signs. A comprehensive step-by-step method of nondestructive remote sensing was developed, including the analysis of high-resolution satellite images in the Google Earth Pro resource, identifying promising areas by plant and landscape features, creating GPS routes for ground reconnaissance, geophysical surveys (magnetic and electromagnetic) on promising areas for identifying Late Bronze Age settlements, GPS mapping of surface material, point archaeological sounding. All the results obtained are placed in a special geo-information system, the substrate layers of which are detailed topographic, soil, geological, hydrogeological, digital relief maps. As a result, 48 new settlements of the Late Bronze Age were identified, including 19 settlements with double stone pens. These pens were first discovered only with help of remote sensing methods, especially magnetic surveying. The final answer about the existence and layout of the settlement of the Late Bronze Age before the archaeological excavations is given only by magnetic and electromagnetic surveys. The GIS created on the monuments of the Late Bronze Age in the North-Western Crimea will serve both scientific purposes and to preserve the cultural heritage of the Republic of Crimea, which is especially important in conditions of rapid economic development of land and the construction of trunk roads.
\end{abstract}

KEYWORDS: remote sensing, GIS, magnetic and electromagnetic surveys, Late Bronze Age settlements, Northwestern Crimea

\section{ВВЕДЕНИЕ}

До 2007 г. в Северо-Западном Крыму было известно только 10 поселений эпохи поздней бронзы [Колотухин, 2003, с. 68, рис. 1]. В ходе наших комплексных разведок 20072019 гг. с применением дистанционных методов в этом регионе выявлено 48 новых поселений позднего бронзового века. Таким образом, их число к настоящему времени увеличилось до 58 (рис. 1).

Выявление поселений эпохи поздней бронзы представляет известную сложность, так как каменные сооружения этого времени почти полностью «утоплены» в землю и не видны на поверхности в силу нарастания с течением времени гумусного слоя почвы. Поэтому для обнаружения поселений позднего бронзового века особенно важно учитывать косвенные природные признаки: густую злаковую растительность в сочетании с проявляющимся в обнажениях и выбросах из нор грызунов и лис, мощный гумусированный грунт золистого цвета, насыщенный обломками костей животных и лепной керамики.

\footnotetext{
${ }^{1}$ V.I. Vernadsky Crimean Federal University, Simferopol, Vernadsky Ave, 4, 295007, Simferopol, Russia; National Research Center "Kurchatov Institute", 1, Academitian Kurchatov Square, Moscow, 123182, Russia; e-mail: tnsmek@mail.ru

${ }^{2}$ Institute of the History of Material Culture, Dvortsovaya quay, 18, Saint-Petersburg, 191186, Russia; e-mail: mirra-k@yandex.ru
} 


\section{МАТЕРИАЛЫ И МЕТОДЫ ИССЛЕДОВАНИЙ}

С 2007 г. археологические разведки поселений эпохи поздней бронзы в Северо-Западном Крыму начали проводиться проводились по мультидисциплинарной методике, сочетавшей дистанционные, геофизические, геохимические и традиционные археологические методы [Смекалова, Кутайсов, 2017, с. 94-95]. На начальном этапе полевых исследований тщательно изучались и анализировались космические снимки на исследуемые площади из общедоступного в настоящее время интернет-ресурса Google Earth Pro. Поселения эпохи бронзы выделяются на весенних космических снимках по пятнам интенсивной растительности, занимающих особые ландшафтные позиции: на мысах сходящихся балок или на их берегах. В программе Google Earth Pro выявлялись перспективные местонахождения, считывались их GPS координаты и прокладывались маршруты для натурных разведок. Последующие автомобильно-пешие обследования имели целью проверку местонахождений, выявленных по данным космических снимков и проведению геофизических съёмок.

Окончательный ответ о существовании и планировке поселения эпохи поздней бронзы дают только магнитная и электромагнитные съёмки, которые проводилась с использованием Оверхаузеровской четырехдатчиковой системы на базе канадского магнитометра GSM-19WG фирмы Gem Systems и электромагнитного измерителя EM38 канадской фирмы Geonix. Дома позднего бронзового века на магнитных картах отражаются в виде положительных аномалий приблизительно прямоугольной формы (магнитное заполнение полуземлянок) с отрицательным обрамлением (немагнитные известняковые стены). На картах магнитного поля положительные магнитные аномалии показаны темным, а отрицательные светлым тоном. На картах электрической проводимости, заснятых с помощью электромагнитного измерителя, над полуземлянками фиксируются положительные аномалии, так как их заполнение лучше проводит электрический ток, чем вмещающая среда [Smekalova et al., 2016].

Только магнитная съёмка на больших площадях, занимаемых двойными каменными загонами, позволила получить полное представление об их размерах и планировке, а также пространственном соотношении с жилыми и хозяйственными постройками на поселении.

Данные об открытых до 2018 г. поселениях были опубликованы нами ранее [Смекалова, Кутайсов, 2017, с. 93-134] (рис. 1). В этой статье мы приводим сведения о трёх новых поселениях, выявленных нашими комплексными разведками в 2018-2019 гг.

Поселение Агар-Су 1 расположено на южном берегу протяжённой балки Агар-Су в её верхнем течении (рис. 1, 32; 2). Здесь боковая балка образует небольшой мыс. Первоначально поселение было выявлено по яркому пятну растительности на весеннем космическом снимке. Затем была проведена магнитная съёмка, которая показала, что на мысу расположен двойной каменный загон (обозначен буквой «А» на рис. 2), выше которого на пологом склоне, вероятно, располагаются небольшие, заглублённые в землю, жилые и хозяйственные отдельно стоящие постройки (обозначены буквами «В» на рис. 2).

Поселение Тарханкут 18 расположено на северном берегу неглубокого, но протяжённого оврага, впадающего в Оленевскую балку, идущую в широтном направлении по центральной оси западной части Тарханкутского п-ва (рис. 1, 25; 3). Территория поселения в настоящее время регулярно распахивается. С помощью магнитной съёмки был обнаружен двойной загон (обозначен буквой «А» на рис. 3) и ещё несколько локальных положительных аномалий (обозначены буквами «В» на рис. 3), которые могут быть остатками заглублённых помещений, разрушенных вспашкой. На этом поселении в 2019 г. было заложено два шурфа: один «перерезал» внешнюю стену загона (1 на рис. 3), второй — внутри заглублённого помещения (2 на рис. 3 ). 


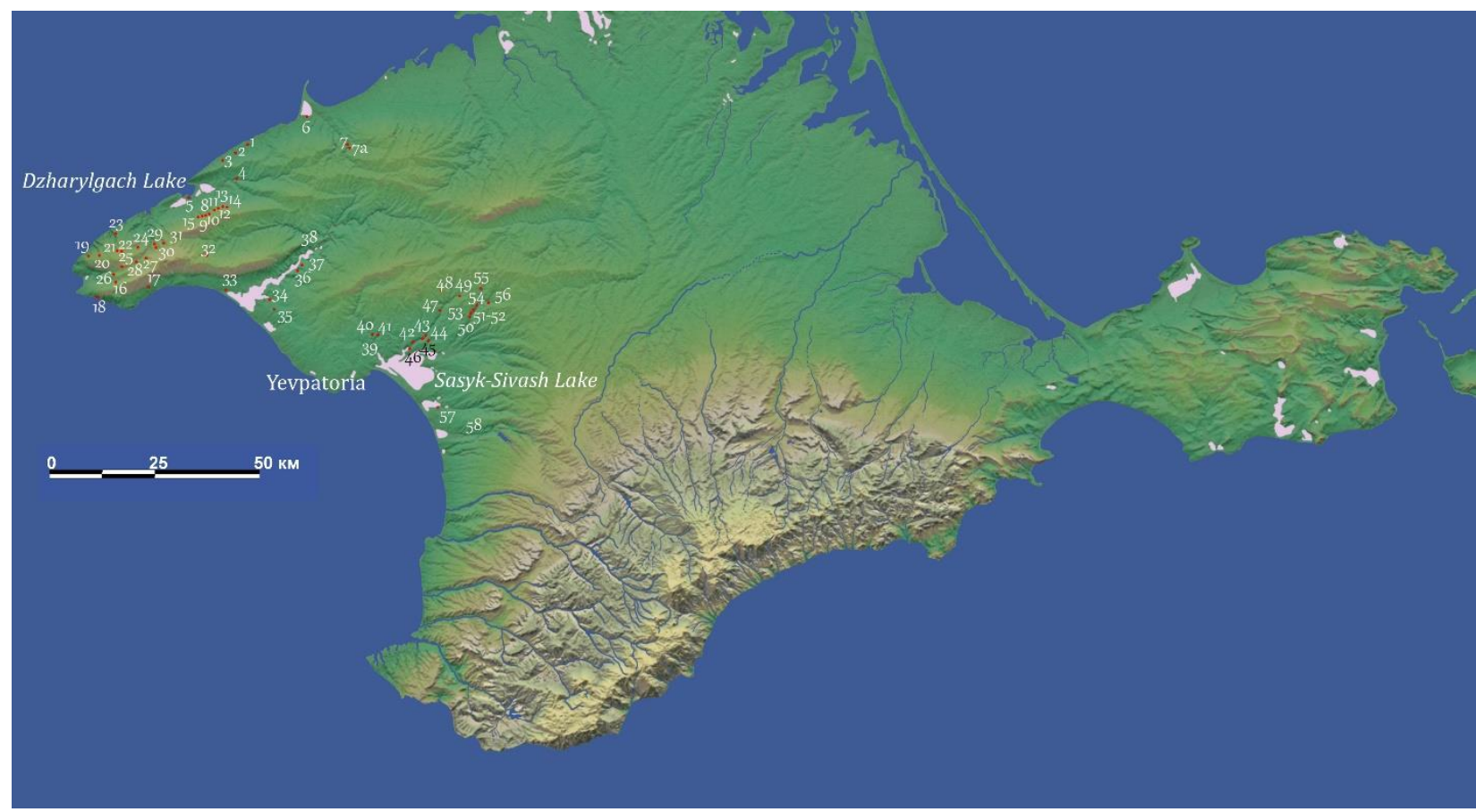

Рис. 1. Поселения позднего бронзового века в Северо-Западном Крыму.

1 - Бурун-Эли, 2 - Бай-Кият, 3 - Скалистое 2, 4 - Водопойное, 5- Ярылгачское Восточное, 6-Бакал 1, 7 - Бакал 2, 7а-Бакал 12, 8- Тарханкут H1, 9-Тарханкут H2, 10 - Тарханкут H6, 11- Тарханкут H9, 12 - Тарханкут H8, 13 - Тарханкут H20,

14 - Тарханкут H14, 15 - Снежное, 16 -Оленевская балка 603, 17 - Марьино 2,

18 - Атлеш, 19 - Джангуль 64, 20 - Мальій Кастель 57, 21 - Тарханкут 22а,

22 - Тарханкут 100, 23 - Тарханкут 167, 24 - Калиновская балка 85, 25 - Тарханкут

18, 26 - Оленевская балка 19, 27 - Кельшейх 87, 28 - Кунан 88, 29 - Кельшейх 46,

30 - Кельшейх 47, 31 - Кельшейх 52, 32 - Агар-Су, 33 - Донузлав 130, 34 - Донузлав

10, 35 - Крыловка, 36 - Донузлав 8, 37 - Донузлав 7, 38 - Донузлав 11,

39-Суворовское, 40 - Багай 1, 2, 41 - Багай 3, 42 - Тюмень 15, 43 - Тюмень 7,

44 - Тюмень 3, 45 - тюмень 1a, 46 - Тюмень 4, 47 - Тюмень 16, 48 - Тюмень 11,

49 - Тюмень 10, 50 - Бораш 2, 51-52 - Бораш 3-4, 53 - Бораш 5, 54-Бораш 6,

55 - Бораш 10, 56 - Бораш 9, 57 - тузла, 58 - Ивановка

Fig. 1. Late Bronze Age settlements in the North-Western Crimea.

1-Burun-Eli, 2 - Bai-Kiyat, 3-Skalistoe 2, 4-Vodopoinie, 5-Eastern Yarylgach,

6-Bakal 1, 7 - Bakal 2, 7a-Bakal 12,8-Tarkhankut H1, 9-Tarkhankut H2,

10 - Tarkhankut H6, 11-Tarkhankut H9, 12 - Tarkhankut H8, 13 - Tarkhankut H20,

14 - Tarkhankut H14, 15 - Snezhnoe, 16 - Olenevskaya Balka 603, 17 - Mar'ino 2,

18-Atlesh, 19-Dzhangul' 64, 20-Malyi Kastel' 57, 21 - Tarkhankut 22a,

22 - Tarkhankut 100, 23 - Tarkhankut 167, 24 - Kalinovskaya Balka 85,

25 - Tarkhankut 18, 26-Olenevskaya Balka 19, 27 - Kel'sheikh 87, 28 - Kunan 88,

29 -Kel'sheikh 46, 30 - Kel'sheikh 47, 31 - Kel'sheikh 52, 32 - Agar-Su,

33 - Donuzlav 130, 34 - Donuzlav 10, 35 - Krylovka, 36 - Donuzlav 8, 37 - Donuzlav 7,

38 - Donuzlav 11, 39 - Suvorovskoye, 40-Bagai 1,2, 41 - Bagai 3,

42 - Tyumen' 15, 43 - Tyumen' 7, 44 - Tyumen' 3, 45 - Tyumen' la, 46-Tyumen' 4,

47 - Tyumen' 16, 48 - Tyumen' 11, 49 - Tyumen' 10, 50-Borash 2,

51-52-Borash 3-4, 53 - Borash 5, 54 - Borash 6, 55 - Borash 10, 56 - Borash 9, 57 - Tuzla, 58 - Ivanovka 


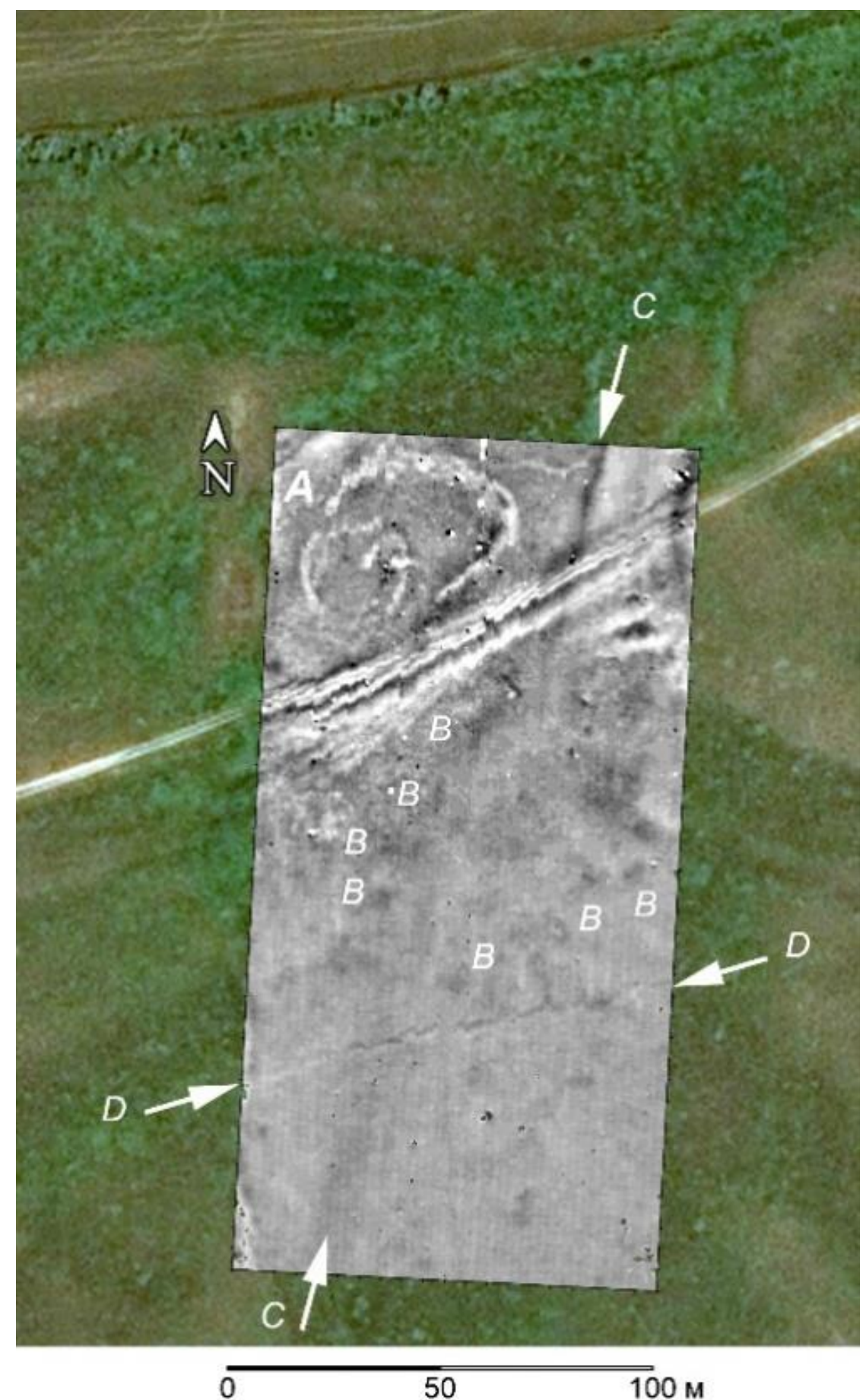

Рис. 2. Магнитная карта поселения Агар-Су, показанная на фоне космического снимка Fig. 2. Magnetic map of the settlement Agar-Su, shown on a background of a satellite image

Поселение Марьино 2 (рис. 1, 17; 4) находится на южном склоне Мелового увала, в верховьях длинной балки, спускающейся к морю между селами Марьино и Окуневка. Магнитная съёмка, проведённая на этом памятнике, выявила круглый двойной загон диаметром ок. 45 м с боковой пристройкой неправильной формы. Жилища на этом поселении пока не обнаружены. Они могут находиться на противоположном берегу балки, где в рельефе местности прослеживается небольшое каменистое всхолмление, что видно из топографической карты, снятой с помощью GPS Trimble R8 в системе координат CK-63 (сечение изолиний $0,2 \mathrm{M})$. 


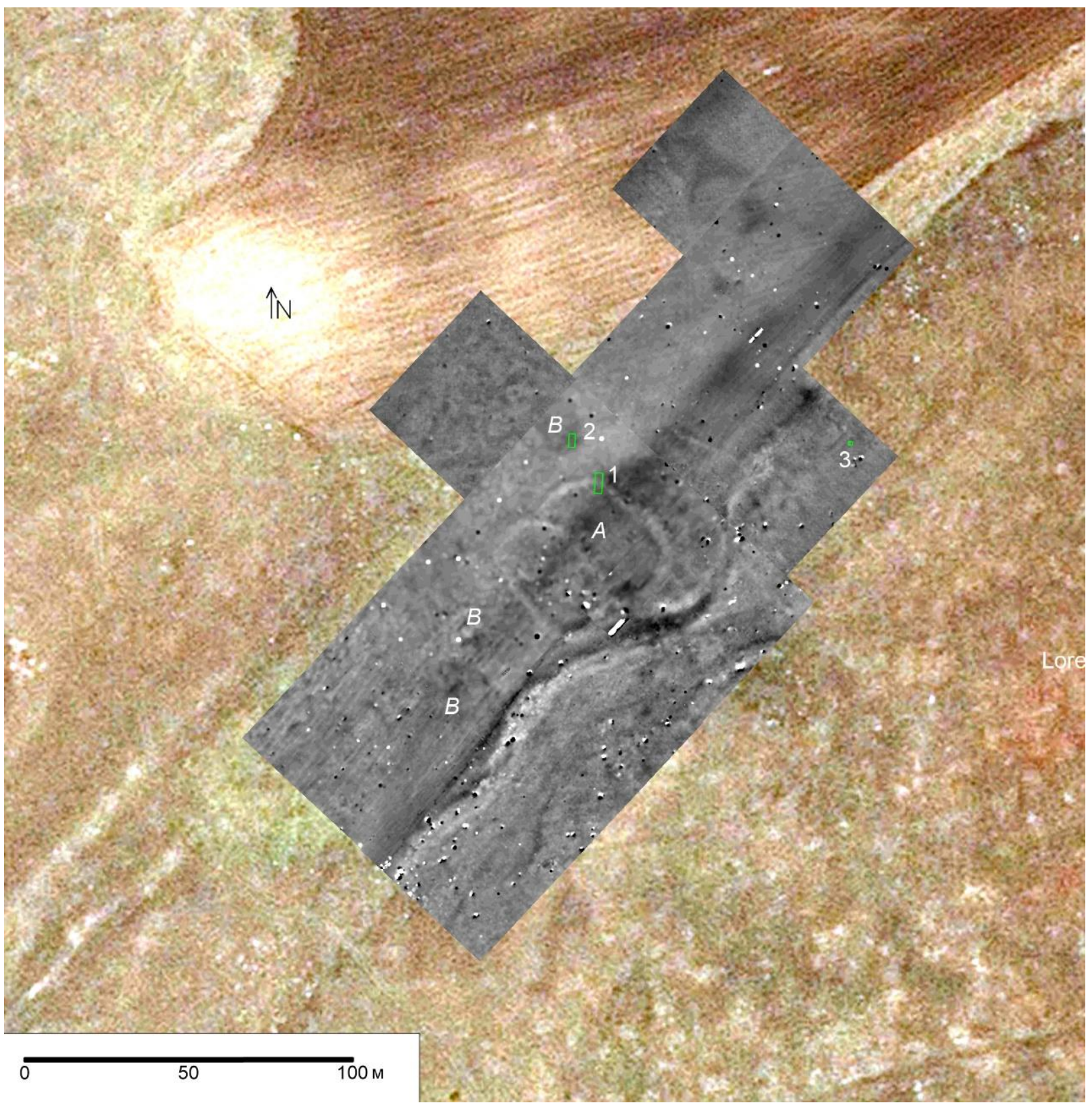

Рис. 3. Магнитная карта поселения Тарханкут 18, показанная на фоне космического снимка

Fig. 3. Magnetic map of the settlement Tarkhankut 18, shown on a background of a satellite image

Таким образом, к настоящему времени мы располагаем общей информацией о 50 поселениях позднего бронзового века в Северо-Западном Крыму, в т.ч. с двойными загонами. Кроме этого, по данным раскопок и магнитной съёмки построены планы 28 поселений, из них 2 поселения раскопаны широкими площадями (Бай-Кият и Бурун-Эли), на 7-и поселениях было осуществлено точечное археологическое зондирование (шурфовка). Материалами этих исследований мы будем оперировать при изучении системы расселения в эпоху позднего бронзового века, иерархии поселений, типов хозяйствования и основ экономики, а также социальной структуры общества. 


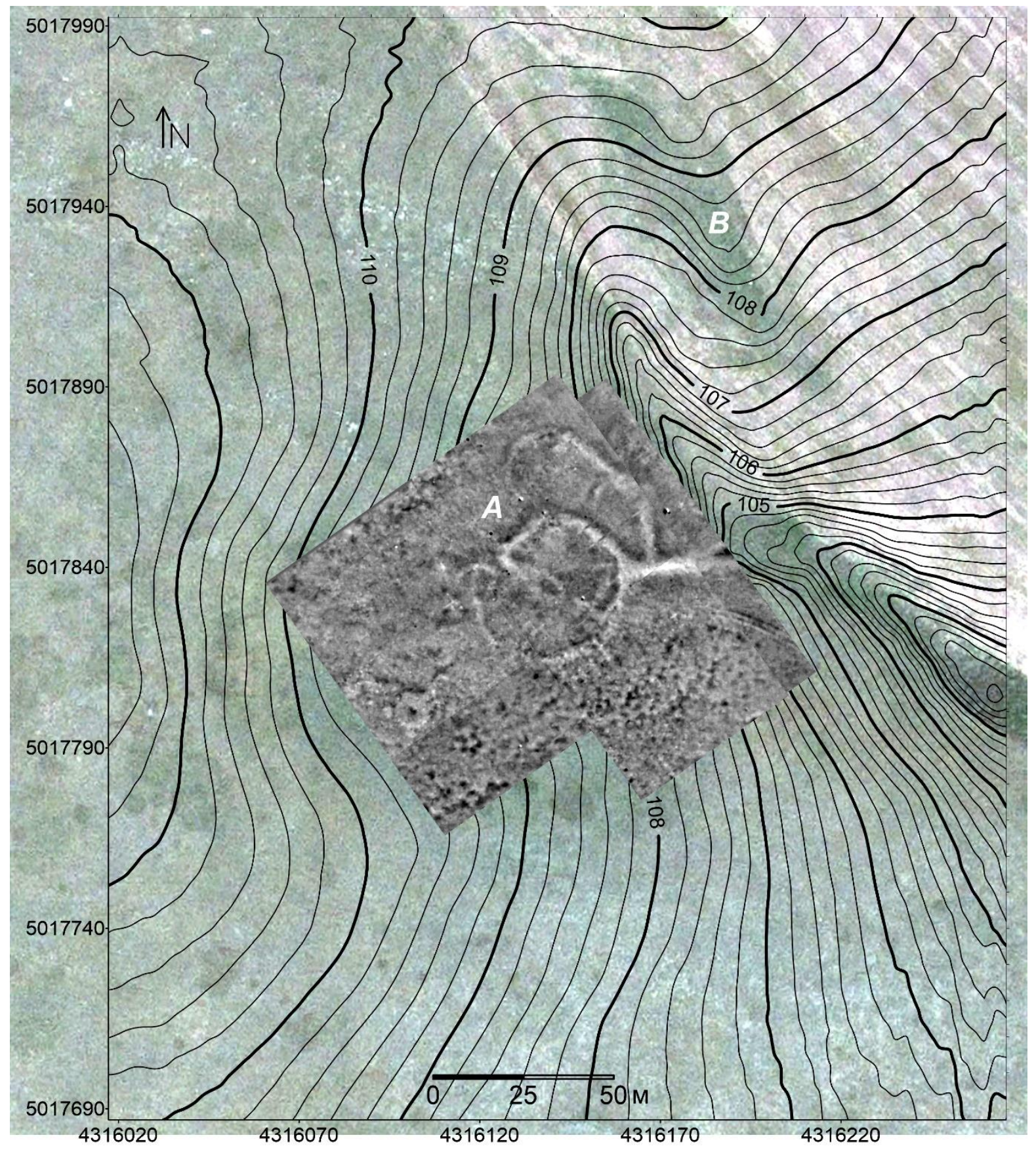

Рис. 4. Магнитная карта поселения Марьино, показанная на фоне космического снимка Fig. 4. Magnetic map of the settlement Mar'ino 2, shown on a background of a satellite image

\section{РЕЗУЛЬТАТЫ ИССЛЕДОВАНИЙ И ИХ ОБСУЖДЕНИЕ Ландшафтная позиция и система расселения}

Основной выявленной нами закономерностью ландшафтной позиции поселений является их расположение в глубинных частях полуострова и приуроченность к особым формам рельефа, а именно, к крупным балочным системам, отдельным балкам или берегам озер. Это особенно наглядно можно проследить на примере прекрасно сохранившегося историко-культурного ландшафта п-ва Тарханкут. Если поместить поселения позднего бронзового века на цифровую карту рельефа полуострова, хорошо видно, что все поселения находятся в пределах мощных балочных систем, развившихся на склонах Мелового и, особенно, Джангульского увалов. По почвенной карте можно заметить, что поселения 
располагаются на границе плодородных чернозёмных пахотных угодий и пастбищ на маломощных карбонатных чернозёмах. Такое расположение поселений наводит на мысль о скотоводческо-земледельческой направленности их хозяйства.

Все поселения занимают особую природную нишу, располагаясь на мысах между двумя сходящимися балками или на их берегах. Такой выбор местоположения поселений объясняется возможностью использования рельефа в целом равнинной местности для укрытия людей и скота от холодных ветров в осенне-зимнее и, особенно, в весеннее время, когда у домашних животных появлялся приплод. Кроме того, данная ландшафтная позиция выгодна и в гидрологическом смысле: у дна глубоких балок, прорезающих многометровую толщу известняков, легче достигнуть водонесущий горизонт путём рытья колодцев. В верховьях оврагов сооружались дамбы для удержания воды в зимне-весенний период. Остатки этих каменных сооружений мы встречаем повсеместно, они особенно ярко выражены на поселении Тарханкут Н2.

Одним из наиболее впечатляющих результатов стало выявление благодаря проведенной масштабной магнитной съёмки на 19 поселениях ранее неизвестных двойных (в единичных случаях - одинарных) конструкций овальной формы с наибольшим диаметром до 50 м, названными «загонами» для скота. Они создают отрицательные аномалии на магнитных картах (на картах - светлые области). Это каменные конструкции с довольно широкими стенами (более $1 \mathrm{~m}$ ), сложенными из известняковых камней разных размеров. На некотором отдалении (до 100-200 м) от этих конструкций обнаружены разнообразные подквадратные, прямоугольные и овальные сооружения, образующие на магнитных картах «ячеистые» положительные аномалии разной конфигурации. Важно отметить, что визуально на современной дневной поверхности эти структуры не видны [Смекалова, Кутайсов 2017, с. 93-94]. Наиболее вероятная хронологическая позиция этих памятников - поздний бронзовый век. Эти выводы были сделаны на основе небольшого количества фрагментов керамики и отдельных находок каменных изделий, поэтому они носят предположительный и предварительный характер. Необходимы новые данные, в том числе полученные путем раскопок и естественно-научных анализов образцов культурного слоя.

Уже обнаружено 19 таких сооружений, долгое время остававшихся неизвестными археологам [Смекалова, Кутайсов 2017, с. 109-131]. Они, возможно, и прежде встречались при раскопках поселений, однако, в силу их больших размеров, никогда полностью не раскапывались и, в связи с этим, не были правильно атрибутированы. Впервые почти полностью подобное сооружение было раскопано только в 2017 г. на поселении бронзового века Госпитальный 2 в связи со строительством автомобильного подъезда к Крымскому мосту. Авторы объясняют назначение постройки как «защищённой площадки для зимнего содержания скота» [Бейлин и др., 2018, с. 12-14]. В том же году на поселении Городище 11 км была раскрыта часть ещё одного подобного сооружения позднего бронзового века, также в рамках работ по строительству трассы «Таврида» [Свиридов и др. 2019], а на поселении Луговое открыты жилища этого же периода [Бонин и дp., 2019]. Реконструированный диаметр предполагаемых загонов составляет 40 м. В обоих случаях авторы соотносят данные сооружения с каменской культурой Восточного Крыма эпохи средней бронзы.

Поиск этнографических параллелей приводит нас в Греческую Македонию, где в горной стране Пиндос до сих пор сохранились каменные и деревянные двойные и тройные загоны, служащие для доения или стрижки овец [Chang, Tourtellotte, 1993, p. 260, fig. 6]. Другая аналогия может быть проведена с зимними пастбищами казахов Семиречья, которые располагались в защищённых от ветра местах на склонах холмов, где рядом с домами ставили загоны для скота и сараи для молодняка [Жолдасбаев, 1989, с. 290-299].

Геохимические анализы грунта заполнения обнаруженных нами двойных оград свидетельствует о том, что они действительно являлись загонами для скота. Так, проведённый А.В. Борисовым (Институт физико-химических и биологических проблем почвоведения РАН) почвенно-химический анализ образца слоя, окружающего каменную стену двойного 
загона на поселении Бакал 2 в Северо-Западном Крыму, показал, что «золистый» цвет почвы является следствием не сжигания, а микробиологической минерализации растительного материала (навоза) и его нагрева вследствие экзотермических реакций при разложении. В почвенном разрезе резко выделяется слой, соответствующий каменному загону, где численность термофилов достигает 0,26 млн, что свидетельствует о накоплении растительного материала и его нагреве вследствие экзотетрмических реакций при разложении [Nielsen, Kristiansen, 2014; Chernysheva et al., 2017]. Природа этого растительного материала, учитывая очень высокие значения уреазной активности, вероятнее всего, связана с содержанием скота.

Геохимические анализы образцов грунта из заполнения каменных оград и этнографические аналогии позволили утверждать, что эти структуры являются загонами для скота с двумя изолированными отсеками для разделения стада по видовому, половозрастному или иному признаку, например, для отделения овец при дойке или стрижке.

Имея в своём распоряжении материал по планиграфии 28 поселений эпохи поздней бронзы в Северо-Западном Крыму, мы можем предпринять попытку их первоначальной классификации. Наиболее очевидное разделение поселений по типам может быть произведено по наличию (Тип 1) или отсутствию (Тип 2) двойного или одинарного загона для скота. Подавляющее большинство поселений с загонами (14 из 19) находится на п-ве Тарханкут, ещё два двойных загона зафиксировано на поселениях у оз. Донузлав, и только три загона зафиксированы в бассейне оз. Сасык-Сиваш.

\section{Тип 1. Поселения с загонами для скота}

К этому типу относятся две трети поселений от общего числа анализируемых (19 из 28). На них обнаружены двойные или одинарные каменные загоны. Эти загоны представляют собой крупные каменные сооружения овальной формы, состоящие из двух отсеков. Форма и размеры загонов и их частей могут быть разными, и по этим различиям нам удаётся выделить локальные группы поселений.

Особенно выделяется Джарылгачская локальная группа, состоящая не менее чем из 9 поселений, находящихся на склонах Джангульского увала, спускающихся к оз. Джарылгач. Эта группа характеризуется очень близкими размерами и формой двойных загонов. На поселениях Тарханкут Н1, Н2 (северный загон), Н6 загоны настолько похожи, что создается впечатление об их постройке одними и теми же людьми, или их соплеменниками, хорошо знакомыми с опытом соседей по содержания скота. Общие размеры двойного загона, в среднем, 48-50 м. Малая часть загона почти точно круглой формы, диаметром в среднем 25 м. Возможно, эта часть загона использовалась для приручения молодых лошадей или других животных, которых тренировали, погоняя по периметру круглого загона, как на арене. Примыкающая к ней бо́льшая часть загона - овальной формы, стены этой части загона обычно более толстые, чем малой круглой части. Возможно, здесь содержали основную часть стада, состоящую из взрослых животных.

\section{Тип 2. Поселения без загонов для скота}

Для этого типа характерна особая планировка поселений, при которой постройки располагаются вдоль плавно изгибающейся линии, вплотную или близко друг к другу, образуя внутри конгломерата построек замкнутое или полузамкнутое пространство. Это свободное пространство, возможно, служило местом ночного содержания скота. Об этом косвенно может свидетельствовать повышенная электрическая проводимость грунта внутри этого замкнутого «двора», что мы определили методом электромагнитной съёмки на поселении Тюмень 15 (рис. $5 a$, б).

В связи с тем что «домов» на поселениях обоих типов обычно несколько, а загонов один или два (или один-два замкнутых «двора» для содержания скота), можно сделать вывод о том, что небольшие родственные группы семей, живших в отдельных домах, совместно владели стадом смешанного состава. 


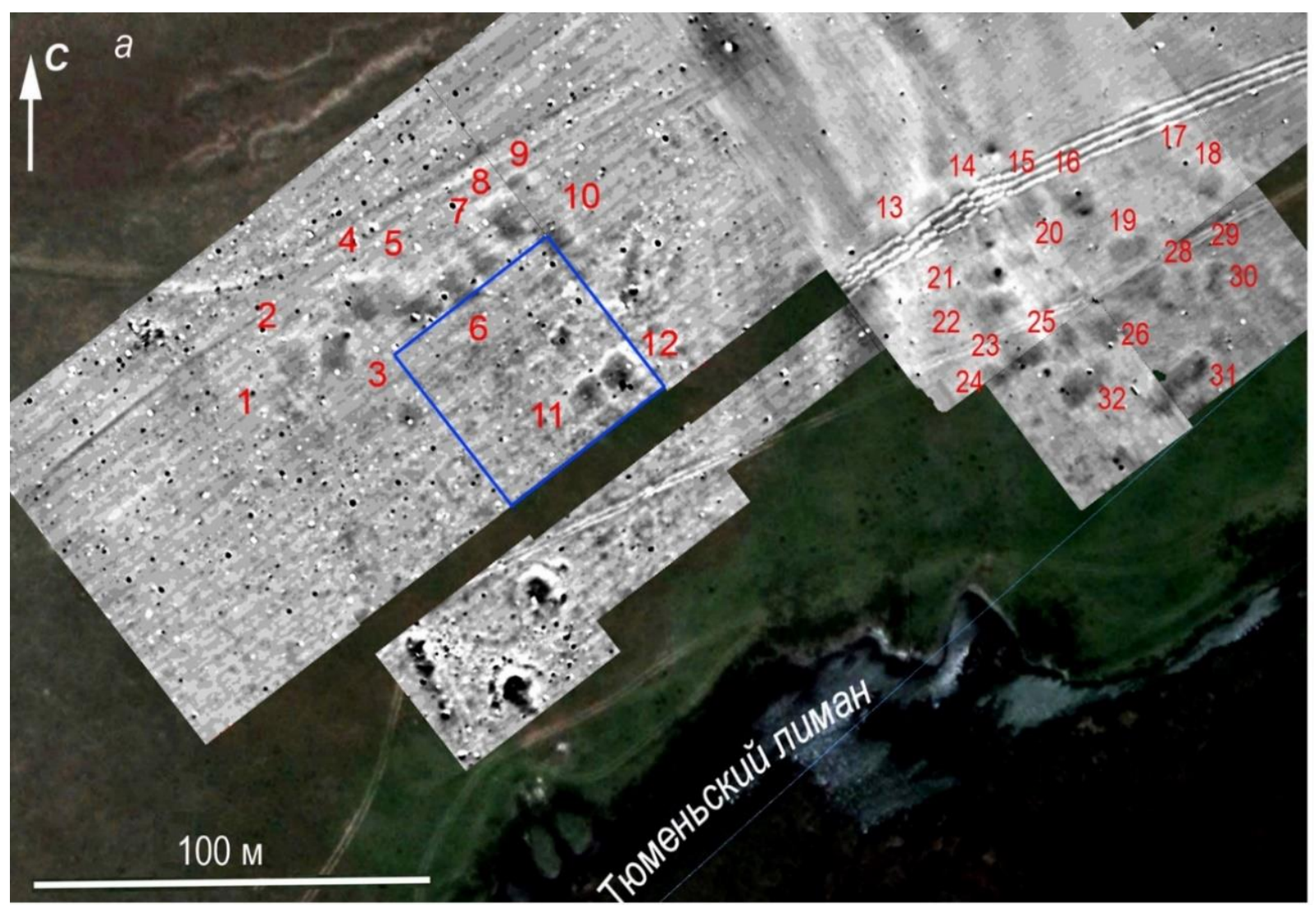

6

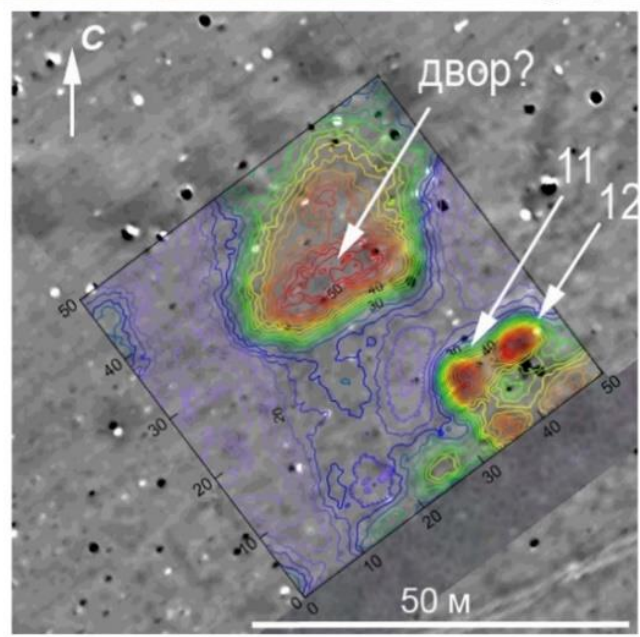

Рис. 5. а-карта магнитного поля поселения Тюмень 15, помещенная на космический снимок. Цифрами отмечены «дома» позднего бронзового века. Синим квадратом отмечена площцадь электромагнитной съёмки, показанная на рис. б - карте изменения электрической проводимости, полученной на части поселения. Цифрами отмечены полуземлянки (11 и 12) и двор, проявившиеся в виде положительных аномалий

Fig. 5. a-map of the magnetic field of Tyumen 15, placed on a satellite image. The numbers indicate the houses of the Late Bronze Age. The blue square marks the area of the electromagnetic survey shown in fig. $b$ - map of electrical conductivity. Numbers mark the half-dugouts (11 and 12) and the courtyard, reflected as positive anomalies

\section{ВЫВОДЫ}

Главным результатом проведённых в Северо-Западном Крыму исследований с помощью дистанционного зондирования (космических снимков и магнитной съёмки) было выявление большого количества поселений эпохи поздней бронзы, в т.ч. с двойными 
загонами для скота, не имеющих явных внешних признаков. Каменные двойные загоны были ранее не известны на поселениях эпохи поздней бронзы и никогда ранее наших исследований археологами в Крыму не обнаруживались. Впервые раскопки подобных сооружений были осуществлены только в 2017 г. на поселениях Госпитальный 2 и Городище 11 км в связи с широкомасштабными раскопками перед строительством трассы «Таврида» на Керченском п-ве.

Безусловно, выявление одинаковых двойных каменных загонов на обширной территории по всему равнинному Крыму - от окрестностей оз. Бакал (Раздольненский р-н) на севере до Тюменьской балочной системы (Сакский р-н) на юге, а также и на Керченском пве в сочетании с полуземляночными жилищами - дает важный материал для изучения вопроса о различиях и сходстве археологических культур и хозяйственных типов населения позднего бронзового века в Северо-Западном и Восточном Крыму. Для характеристики этого населения необходимы дальнейшие исследования по разработанной нами междисциплинарной методике, а также раскопки.

\section{БЛАГОДАРНОСТИ}

Исследование выполнено при финансовой поддержке РФФИ в рамках научного проекта № 18-00-00563 K (18-00-00486).

\section{ACKNOWLEDGEMENTS}

The reported study was funded by RFBR according to the Research Project No 18-0000563 K (18-00-00486).

\section{СПИСОК ЛИТЕРАТУРЫ}

1. Бейлин Д.В., Кисльй А.Е., Михайлов А.М., Рогудеев В.В., Шарапа А.В., Юрочкин В.Ю. Раскопки поселения эпохи бронзы Госпиталь II в г. Керчи (предварительное сообщение). Древности Боспора, 2018. Т. 23. С. 9-35.

2. Бонин А.В., Буравлев С.А., Ермолин С.А. Раскопки поселения бронзового века Луговое Северо-Западное 2 в Восточном Крыму. Крым-Таврида. Археологические исследования в Крыму в 2017-2018 гг.: в 2 т. М., 2019. Т. 1. С. 361-379.

3. Жолдасбаев С.Ж. Зимовки-поселения и жилища казахов Семиречья (XVI-XIX вв.) Взаимодействия кочевых культур и древних цивилизаций. Алма-Ата, 1989. 464 с.

4. Колотухин В.А. Поздний бронзовый век Крыма. Киев: Стилос, 2003. 138 с.

5. Свиридов А.Н., Язиков С.В., Топоривская М.А., Фролов В.В. Раскопки поселения Городище 11 км в 2017 году. Крым-Таврида. Археологические исследования в Крыму в 2017-2018 гг.: в 2 т. М., 2019. Т. 1. С. 187-203.

6. Смекалова T.Н., Кутайсов В.А. Археологический атлас Северо-Западного Крыма. Поздний бронзовый век. Ранний железный век. СПб: Алетейя, 2017. 448 с.

7. Chang C., Tourtellotte P.A. Ethnoarchaeological Survey of Pastoral Transhumance Sites in the Grevena Region, Greece. Journal of Field Archaeology, 1993. V. 20. P. 249-264.

8. Chernysheva E., Korobov D., Borisov A. Thermophilic microorganisms in arable land around medieval archaeological sites in Northern Caucasus, Russia: Novel evidence of past manuring practices. Geoarchaeology, 2017. V. 32 (4). P. 494-501.

9. Nielsen N.H., Kristiansen S. Identifying ancient manuring: traditional phosphate vs. multi-element analysis of archaeological soil. Journal of Archaeological Science, 2014. V. 42. P. 390-398. 10. Smekalova T.N., Yatsishina E.B., Garipov A.S., Pasumanskii A.E., Ketsko R.S., Chudin A.V. Natural science methods in field archaeology, with the case study of Crimea. Crystallography Reports, 2016. V. 61. P. 533-542. 


\section{REFERENCES}

1. Beilin D.V., Kisly A.E., Mikhailov A.M., Rogudeev V.V., Sharapa A.V., Yurochkin V.Yu. Excavations of a settlement of the Bronze Age Hospital II in Kerch (preliminary report). Antiquities of the Bosporus, 2018. V. 23. P. 9-35 (in Russian).

2. Bonin A.V., Buravlev S.A., Ermolin S.A. Excavations of a settlement of the Bronze Age Lugovoye North-West 2 in Eastern Crimea. Crimea-Tavrida. Archaeological Investigations in Crimea in 2017-2018. Moscow, 2019. V. 1. P. 361-379 (in Russian).

3. Chang C., Tourtellotte P.A. Ethnoarchaeological survey of pastoral transhumance sites in the Grevena region, Greece. Journal of Field Archaeology, 1993. V. 20. P. 249-264.

4. Chernysheva E., Korobov D., Borisov A. Thermophilic microorganisms in arable land around medieval archaeological sites in Northern Caucasus, Russia: Novel evidence of past manuring practices. Geoarchaeology, 2017. V. 32 (4). P. 494-501.

5. Kolotukhin V.A. Late Bronze Age of Crimea. Kiev: Stylos, 2003. 138 p. (in Russian).

6. Nielsen N.H., Kristiansen S. Identifying ancient manuring: traditional phosphate vs. multi-element analysis of archaeological soil, Journal of Archaeological Science, 2014. V. 42. P. 390-398. 7. Smekalova T.N., Kutaisov V.A. Archaeological atlas of the North-Western Crimea. Late Bronze Age. Early Iron Age. St. Petersburg: Aletheia, 2017. 448 p. (in Russian).

8. Smekalova T.N., Yatsishina E.B., Garipov A.S., Pasumanskii A.E., Ketsko R.S., Chudin A.V. Natural science methods in field archaeology, with the case study of Crimea. Crystallography Reports, 2016. V. 61. P. 533-542.

9. Sviridov A.N., Yazikov S.B., Toporivskaya M.A., Frolov V.V. Excavations of the settlement Gorodische $11 \mathrm{~km}$ in 2017. Crimea-Tavrida. Archaeological Investigations in Crimea in 2017-2018. Moscow, 2019. V. 1. P. 187-203 (in Russian).

10. Zholdasbaev S.Zh. Winter settlements and dwellings of Kazakhs of Semirech'e $\left(16^{\text {th }}-19^{\text {th }}\right.$ centuries). Interaction of nomadic cultures and ancient civilizations. Alma-Aty, 1989. 464 p. (in Russian). 